\title{
Review Article \\ Bibliometric Study of Pain after Spinal Cord Injury
}

\author{
Yi-Zu Wang $\mathbb{D},{ }^{1}$ Cheng-Cheng Wu $\mathbb{D}^{1},{ }^{1}$ and Xue-Qiang Wang $\mathbb{D}^{1,2}$ \\ ${ }^{1}$ Department of Sport Rehabilitation, Shanghai University of Sport, 399 Changhai RD, Shanghai 200438, China \\ ${ }^{2}$ Department of Rehabilitation Medicine, Shanghai Shangti Orthopaedic Hospital, 188 Hengren RD, Shanghai 200438, China
}

Correspondence should be addressed to Xue-Qiang Wang; qiang897@163.com

Received 30 November 2020; Revised 31 January 2021; Accepted 9 February 2021; Published 20 February 2021

Academic Editor: Yazhuo Kong

Copyright (C) $2021 \mathrm{Yi}-\mathrm{Zu}$ Wang et al. This is an open access article distributed under the Creative Commons Attribution License, which permits unrestricted use, distribution, and reproduction in any medium, provided the original work is properly cited.

Background. The prevalence of comorbid pain after spinal cord injury (SCI) is relatively high in clinical observations and has continued to increase over time. Neuropathic pain (70.14\%) is the most popular subject in academic journals after SCI. However, studies that used the bibliometric method to analyze comorbid pain after SCI are still lacking. This study is aimed at combining and integrating acquired information to analyze the global trends of research on the comorbidity of pain after SCI in the last three decades (1990-2019). Methods. Systematic works of literature published from 1990 to 2019 were obtained from the Web of Science Core Collection. CiteSpace software was used to analyze the relationship of publication year with the country, institution, journals, authors, references, and keywords. The regression analysis is used to evaluate the percentage of the category increase or decrease over time significantly. IBM SPSS Statistics was used in the statistical analysis. Results. A total of 730 publications were included in the analysis. A remarkable increase in the number of publications was observed in the study period $(P<0.05)$. A total of 202 academic journals focused on the categories of clinical neurology, neurosciences, and rehabilitation, and the annual growth rate of articles in these three categories was statistically significant $(P<0.05)$. The USA (356, 48.77\%) and the University of Miami $(64,8.77 \%)$ were the country and institution with the highest number of publications, respectively. Spinal Cord, which was the main journal for research on pain after SCI, had the most publications $(88,12.05 \%)$. Burst keywords showed that the individual, inflammation, and central sensitization with pain after SCI are the research development trends and focus in this research field. Conclusions. Overall, this study provides the latest research direction for pain after SCI. This historical overview of research into pain after SCI will be a useful basis for further research into development trends, focus issues, cooperators, and cooperative institutions.

\section{Introduction}

Pain is a frequent complication of spinal cord injury (SCI), and approximately half to two-thirds of patients with SCI suffer from pain; pain after SCI is typically chronic and neuropathic [1-3]. The male-to-female ratio of SCI is high. Most cases are caused by traffic accidents, falls, sport activities, or violence [4]. SCI causes permanent disabilities and brings a heavy burden to people's quality of life, level of functioning, and chances of returning to work [5]. Pain after SCI manifests in many ways. More than $50 \%$ of patients with SCI suffered chronic pain within 1 year after SCI [6]. The presence of chronic pain seriously affects the patients' daily life and the social impact. Chronic pain in SCI is related to great emotional distress, and pain hinders the ability of SCI patients to participate in active rehabilitation programs [7]. Acute pain is accompanied by injury and recovery and subsides as tissue scars fade, whereas chronic pain occurs because of poor neuroplasticity $[8,9]$. Pain after SCI is difficult to treat because the underlying mechanisms are not yet fully understood. At present, the larger proportion of patients with SCI in most countries and regions is under 30 years old, and the highest incidence rate of 49 every 1 million was recorded in New Zealand [10]. Pain after SCI also brings a medical and economic burden to the government. People with pain after SCI in Canada spend more than US\$2.67 billion annually [11].

In view of the high incidence of pain after SCI, a growing number of researchers have studied pain after SCI, and relevant articles have been published in academic journals. A number of randomized controlled trials have studied the treatment of pain after SCI [12-15]. Scientific research 
studies increasingly apply bibliometrics in quantitative analysis [16-18]. Bibliometric analysis revealed that research on the application of stem cells in SCI is a rapidly developing research field [19]. However, a quantitative analysis of pain associated with SCI has not yet been conducted.

To address the shortage of quantitative analysis of pain after SCI research, the purpose of this study is to provide a basis for the global scientific research on pain after SCI over the last 30 years (1990-2019). By being able to understand the types of pain after SCI in the past 30 years, current research hotspots provide a theoretical basis for follow-up research. Papers using CiteSpace are on the rise, especially in the medical field, where there have been many related studies [20-22]. CiteSpace 5.6.R5 (Drexel University, Philadelphia, USA) is a commonly used software application for bibliometric analysis. The global research trend on pain after SCI includes four aspects: the number of published papers; the distribution and cooperation between authors, institutions, and countries; a citation burst analysis of keywords; and the cocitation analysis of authors and references.

\section{Methods}

2.1. Search Strategy. The publications included in this study were those published within the last 30 years (1990-2019). The publications were downloaded from the Science Citation Index Expanded (SCI-Expanded) Web of Science (WoS). The search strategy was as follows: ([TI=spinal cord injury $]$ OR $[\mathrm{TI}=$ spinal cord injuries $]$ ) AND ([TI= pain $]$ OR $[\mathrm{TI}=$ painful $]$ ).

2.2. Inclusion Criteria and Exclusion Criteria. Publications related to pain and SCI, such as articles, reviews, letters, and editorial materials, published in different academic journals were included. 872 articles were identified from the Web of Science Core Collection. Conference presentations, meeting abstracts, book reviews, news items, and corrections were excluded. After excluding 136 articles, 736 articles were included. No other specific limitation was imposed except that the chosen language was English. Six non-English language papers were excluded. Finally, 730 articles were included.

2.3. Data Extraction. We followed a previous search strategy to search through the WoS database and then imported the gathered information to CiteSpace for analysis [22-25]. We obtained bibliometric indicators by calculating the number of publications, journals, references, citations, extracted $\mathrm{H}$ index, and keywords. The $H$-index is a mixed quantitative index that can be used to evaluate the amount and level of the academic output of researchers. The $H$-index means that an academic journal or researcher has at least $H$ published papers that have at least $H$ citation times per paper. For instance, an $\mathrm{H}$-index of 20 indicates that academic journals or researchers had at least published 20 papers, and the citation frequency is at least 20.

2.4. Statistical Methods. We used CiteSpace 5.6.R5 and Microsoft Excel 2016 to extract and analyze the number of publications (including different journals, countries, institutions, and authors), citation frequency, and keyword trends. We visualized the structure, regular pattern, and distribution of scientific knowledge using CiteSpace and Microsoft Excel:

(1) Analysis of the distribution and trend of journals, countries, institutions, and authors

(2) Analysis of the number of papers, citations, citations per paper, and open-access papers and $H$-index in the top 10 journals

(3) Assess country-to-country cooperation/institutions/ authors

(4) Citation analysis and $H$-index refer to the number of published papers or research $H$ and at least $H$ paper quality

(5) Analysis of citations and keywords

(6) Cocitation analysis according to references, cited authors, and cited journals

(7) Cooccurrence analysis of terms, keywords, sources, and categories

Besides, we calculated the number of single-author and multiauthor publications, the frequency of WoS subject categories, and types of pain category ranking percentage scores annually (the number of publications every year divided by the total number of publications in each category). The regression analysis is used to evaluate the percentage of the category increase or decrease over time significantly (the category as the dependent variable and the year as the independent variable). SPSS Statistics 22.0 software (Chicago, USA) was used for statistical analysis. $P<0.05$ was considered statistically significant.

\section{Results}

3.1. Publication Output and Growth Trends. A total of 730 articles were included (Supplementary Figure 1). According to Figure 1(a), although the number of publications has increased and decreased over the past 30 years, the overall trend has continued to increase. The initial three publications increased to 47 publications from 1990 to 2019 (Figure 1(a)). The number of articles published in 2017 was 66. The results of linear regression analysis indicated that the number of articles published increased significantly with time over the last 30 years $(t=14.762$, $P<0.001)$. The number of citations increased from 0 citations in 1990 to 2397 citations in 2019. A total of 26,232 citations are cited in all the papers with an average of 874.4 times per year. Figure 1(b) shows that the number of article citations had a significant increase over time $(t=17.066$, $P<0.001)$. We divided the study period of 30 years into six groups (1990-1994, 1995-1999, 2000-2004, 20052009, 2010-2014, and 2015-2019). The largest number of citations per paper was 423.89 from 1995 to 1999. The highest $H$-index value was 110 , and the most cited papers were from 2010 to 2014 (826). The most published papers 


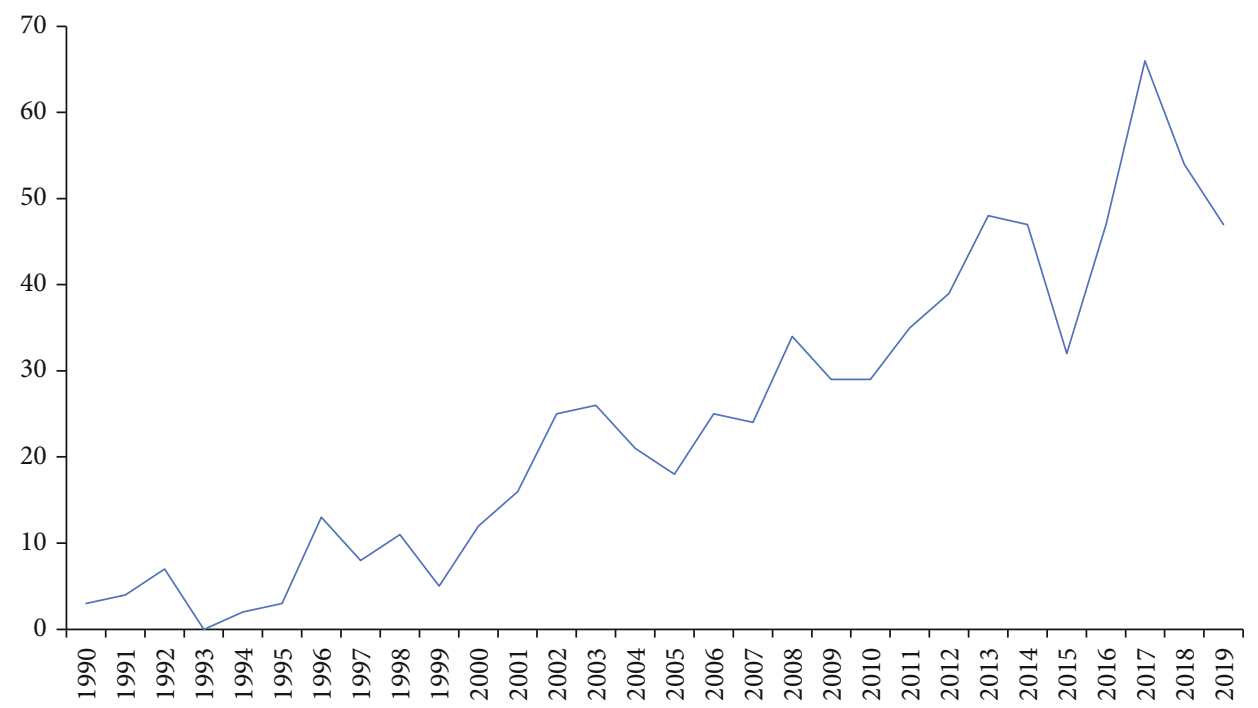

(a)

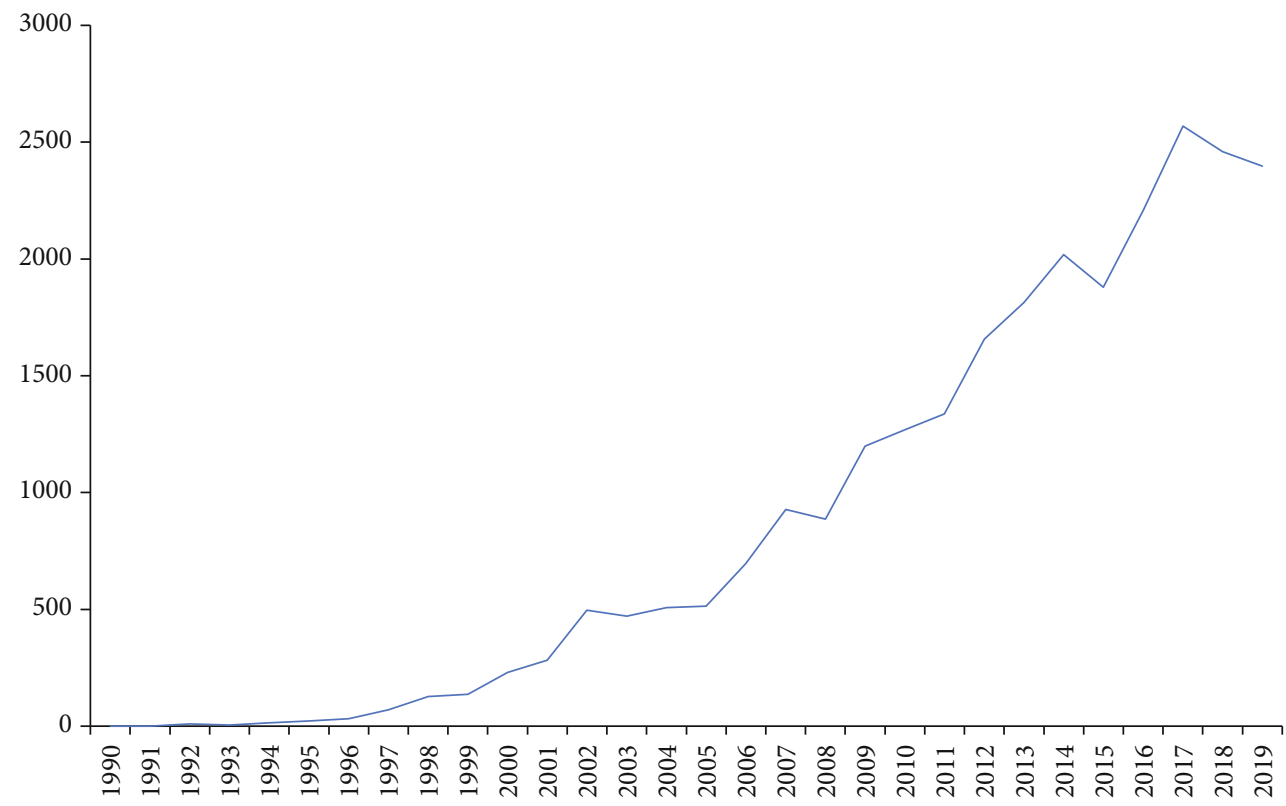

(b)

Figure 1: Number of publications and citations. (a) The number of annual publications on pain after spinal cord injury research from 1990 to 2019. (b) The number of annual citations on pain after spinal cord injury research from 1990 to 2019.

(247) and the highest number of open-access papers (145) were recorded in 2015-2019 (Figure 2). And the results of linear regression analysis of the $H$-index value and the number of open-access papers also have a significant increase with time over the last 30 years $(t=4.252, P<$ $0.001 ; t=8.823, P<0.001)$.

3.2. Distribution by Journals. Supplementary Table 1 shows that 730 articles were selected through WoS screening, and these 730 articles were published in 202 academic journals. We selected the top 20 of these 202 academic journals according to the number of publications (Table 1). The total number of published articles in the top 20 academic journals exceeded half of the total number of articles
(58.91\%). The academic journal Spinal Cord had published the largest number of articles (88 publications, 12.06\%), and its impact factor (IF) is 1.773 . Pain, which has an IF of 5.483 , contributed to the second most published articles (60 publications, 8.22\%). The Archives of Physical Medicine and Rehabilitation (IF 2019, 3.098; 41 publications, 5.62\%), Journal of Neurotrauma (IF 2019, 3.793; 33 publications, 4.52\%), and Journal of Spinal Cord Medicine (IF 2019, 1.816; 28 publications, $3.84 \%$ ) ranked the third to fifth, respectively, in terms of the number of publications. The Pain journal had the highest number of citations (4845) and the highest $H$-index value (37). Neurology had the highest IF amongst the top 20 journals (IF 2019, 8.77), and Journal of Neuroscience had the largest number of citations 


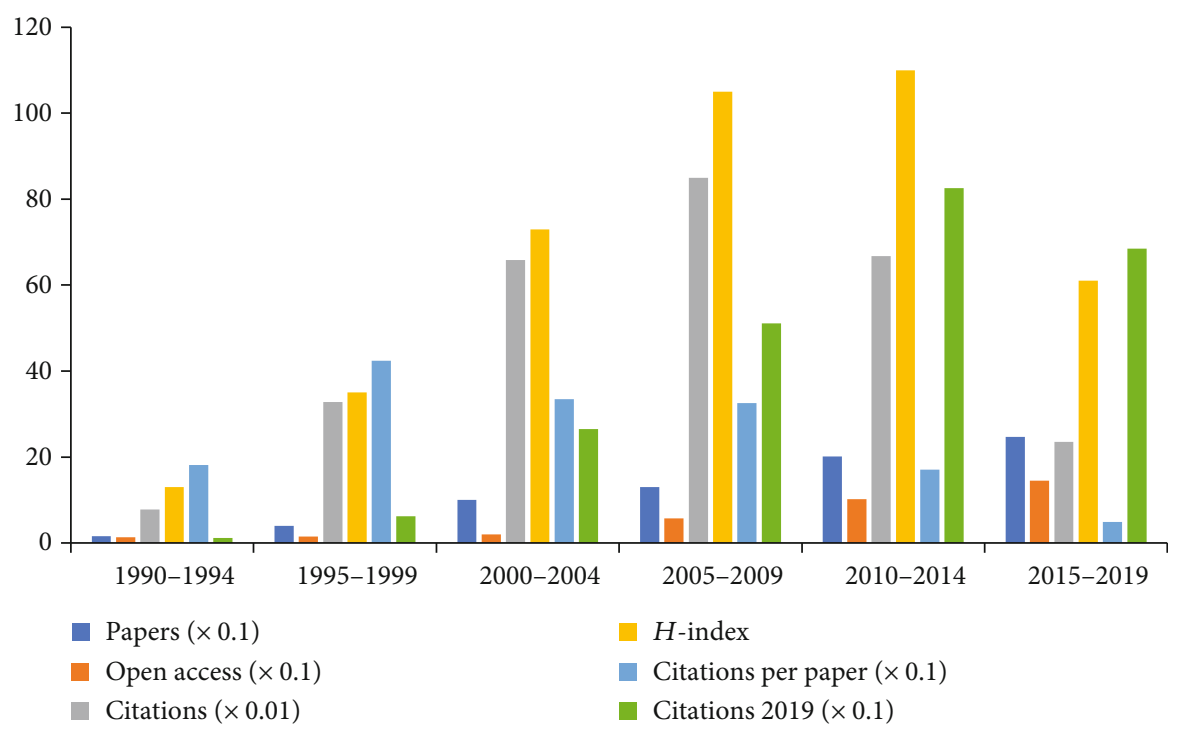

Figure 2: Number of papers, citations, citations per paper, open-access papers, and citations in 2019 and $H$-index for each 5-year time period.

per paper (116.36). In accordance with the journal IF quartile of WoS, 35\% of the 20 journals were in the first quartile (Q1), and $45 \%$ of the journals were in the second quartile $(\mathrm{Q} 2)$.

Figure 3 indicates the dual map of the journal. The map on the left represents the citing journals, and the map on the right represents the cited journals. In the dual-map overlay, the labels are marked according to the disciplines of the subject. A line connects the citing journal on the left side to the cited journal on the right side. The dual map indicates that most of the journals were from the molecular, biology, and immunology fields. Simultaneously, most journals were cited from the molecular, biology, and genetics fields.

3.3. Subject Categories of WoS. We classified the 730 articles into the 51 subject categories of WoS and ranked the top 20 journals on the basis of the number of publications (Figure 4). Anesthesiology was the subject category with the largest number of citations per paper (54.85). Clinical neurology had the largest number of publications (355), citations $(13,008)$, and open-access papers (181) and the highest $H$ -index (70).

3.4. Types of Pain. The top 10 types of pain after SCI were ranked as shown in Figure 5. Neuropathic pain (70.14\%) is the most popular subject after SCI. Moreover, neuropathic pain had the highest number of publications (512), citations $(16,045)$, and open-access papers (268) and the highest $H$ -index value (77). Notably, average musculoskeletal muscle pain had the most citations per article (67.17).

3.5. Distribution by Countries and Institutions. The 730 articles on pain after SCI were contributed by 42 countries or regions (Supplementary Table 2). Figure 6 shows the top 10 countries or regions according to the number of publications. The United States of America (USA) had the highest number of publications (356), citations $(13,874)$, and open-access papers (168) and the highest $H$-index value (70), followed by Australia (53), which had the most citations per paper (63.06), and China (53). Figure 7(a) indicates that the contributing countries/regions have extensive and close cooperation and contact. The countries or regions of the included 730 articles are presented in the world map in Figure 8.

A total of 795 institutions (Supplementary Table 3) contributed to 730 papers on pain after SCI. Supplementary Figure 2 indicates the top 10 institutions in terms of the number of published papers. The University of Miami had the largest number of publications (64) and open-access papers (64) and the highest $H$-index (31). The University of Seattle and the University of Washington had the largest number of citations (2605). The University of Texas Medical Branch Galveston had the largest number of citations per paper (81.56). Figure $7(\mathrm{~b})$ indicates the collaborations between institutions. The University of Miami and the University of Sydney had a strong partnership.

3.6. Distribution by Authors. The 730 articles were contributed by 1000 authors. The top 10 authors and cocited authors were ranked based on the number of journals published (Table 2). Finnerup NB, who published 34 articles, ranked first, followed by Cardenas DD (29 publications) and Siddall PJ (27 publications). Siddall PJ was cocited 403 times, followed by Finnerup NB (269 times) and Widerstromnoga EG (164 times). Figure 9 indicates the cooperation between authors. Amongst the authors, Cardenas DD not only has many cooperative relations with Jensen MP but also has close cooperation with Turner JA. There is also close cooperation between Finnerup NB, which has the highest number of publications, and Siddall PJ, who ranks third in the number of publications. The proportion of single authors and multiple authors (authors $\geq 2$ ) every 5 years is shown in Figure 10. The linear regression results showed that the percentage of papers with a single author significantly decreased $(t=-3.557, P<0.05)$ over time. 


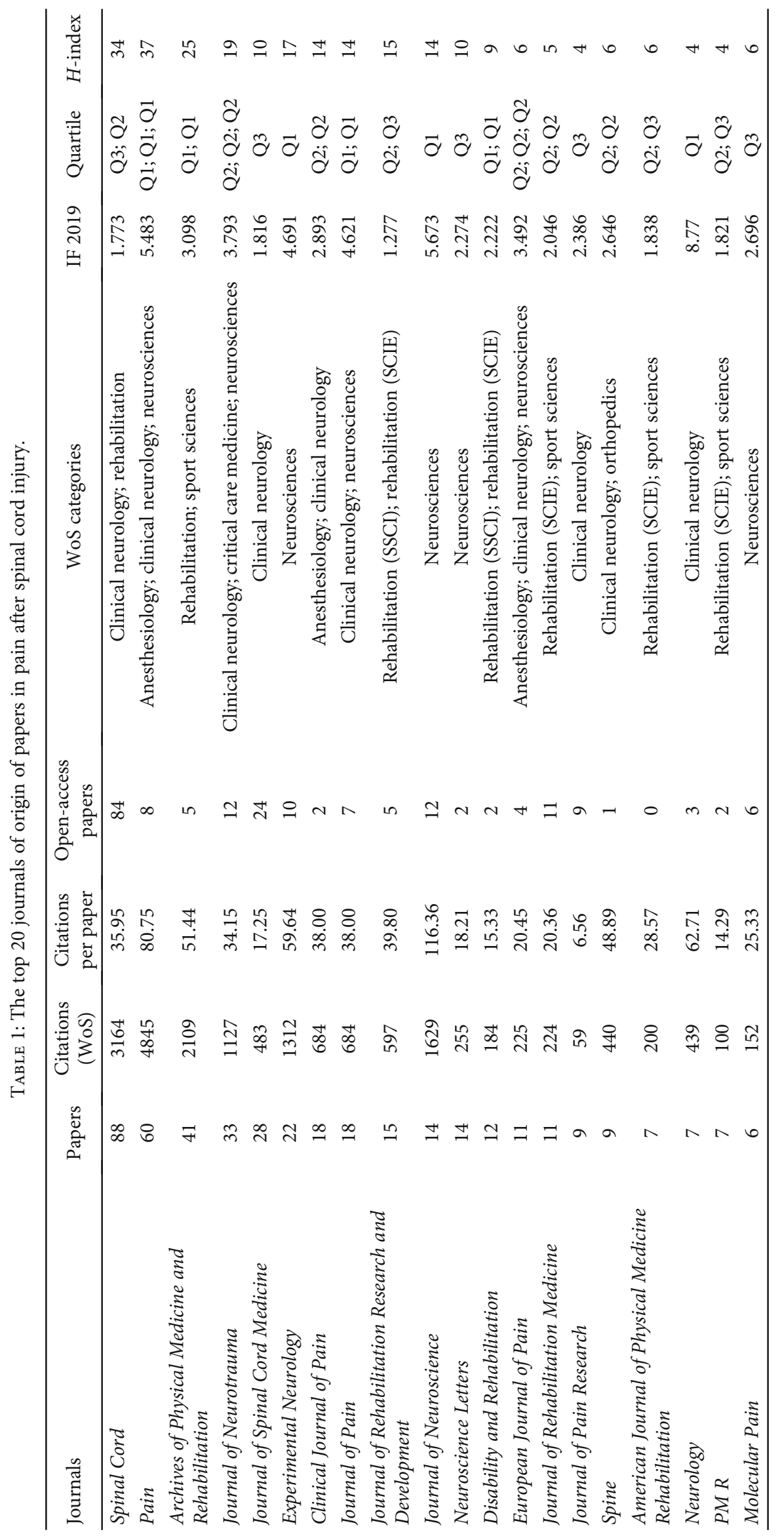




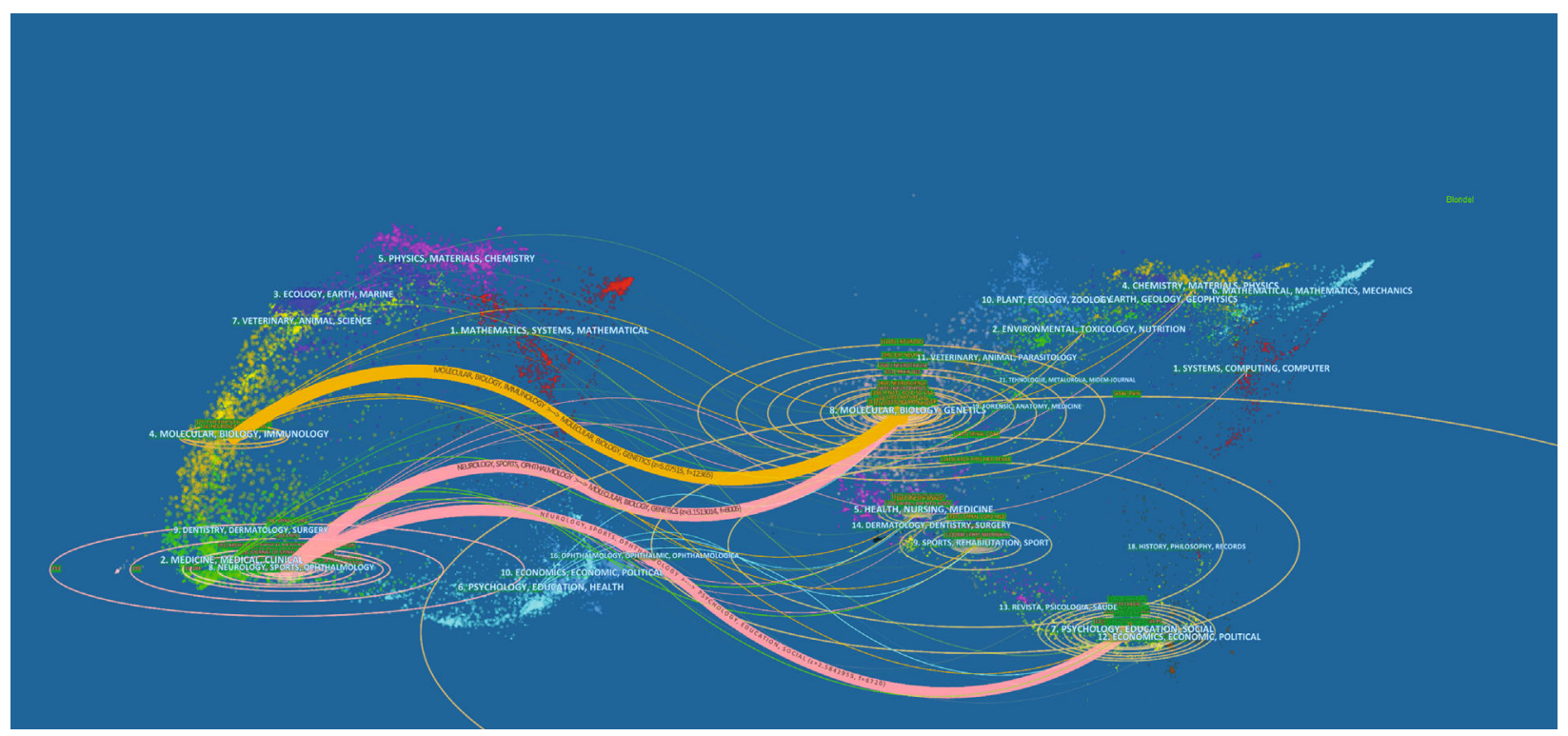

FIGURE 3: The dual-map overlay of journals related to pain after spinal cord injury.

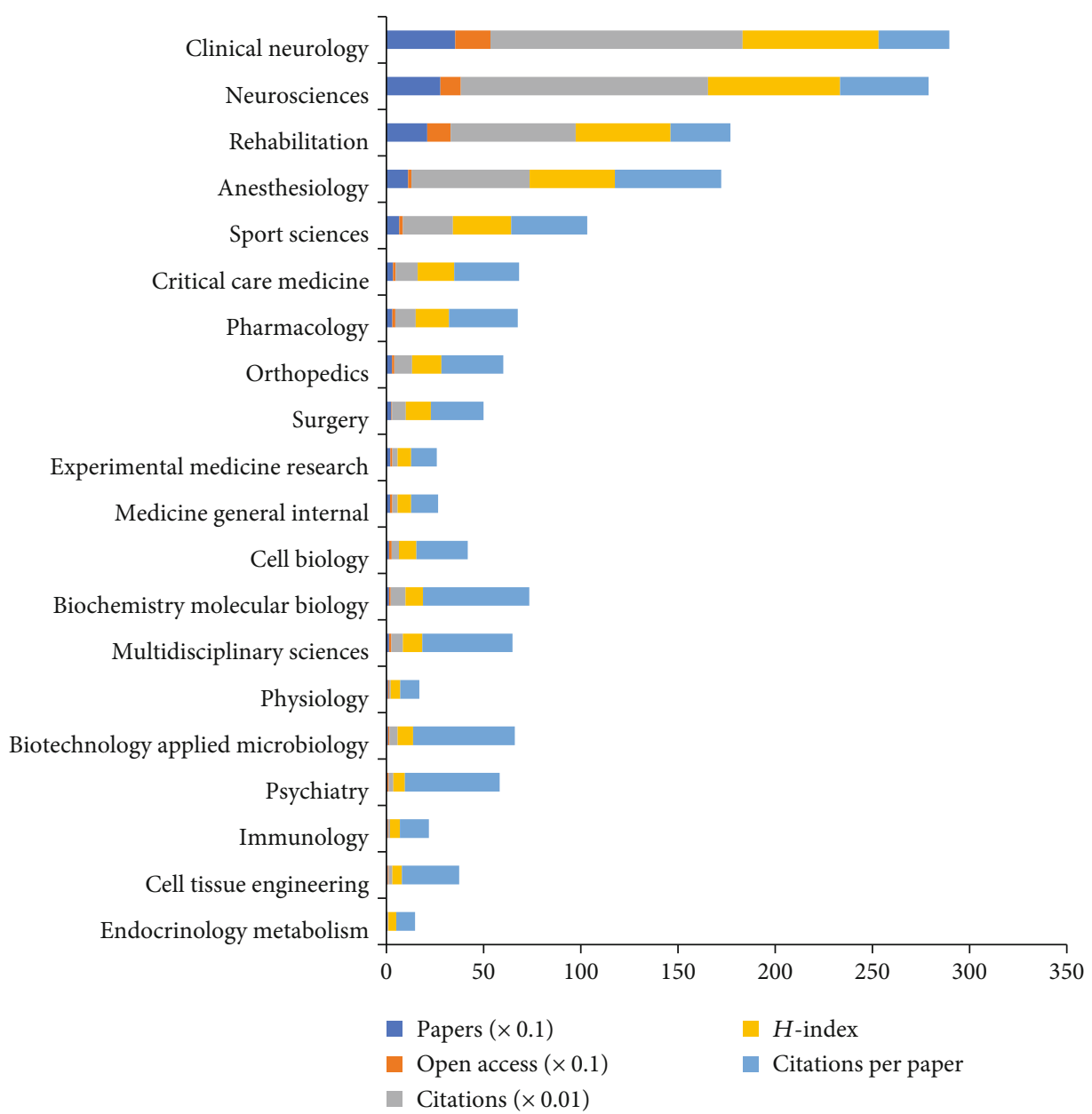

Figure 4: The number of papers, citations, citations per paper, and open-access papers and $H$-index of the top 20 subject categories of Web of Science. 


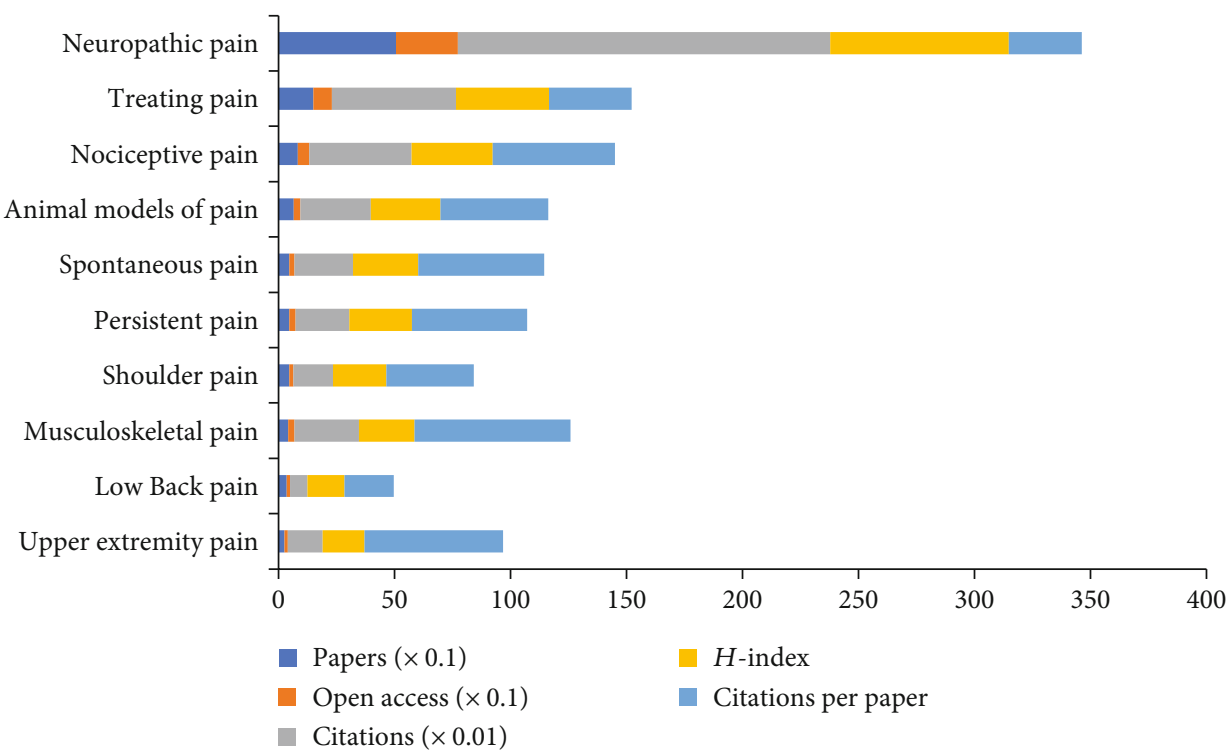

FIGURE 5: The number of papers, citations, citations per paper, and open-access papers and $H$-index of the top 10 types of pain.

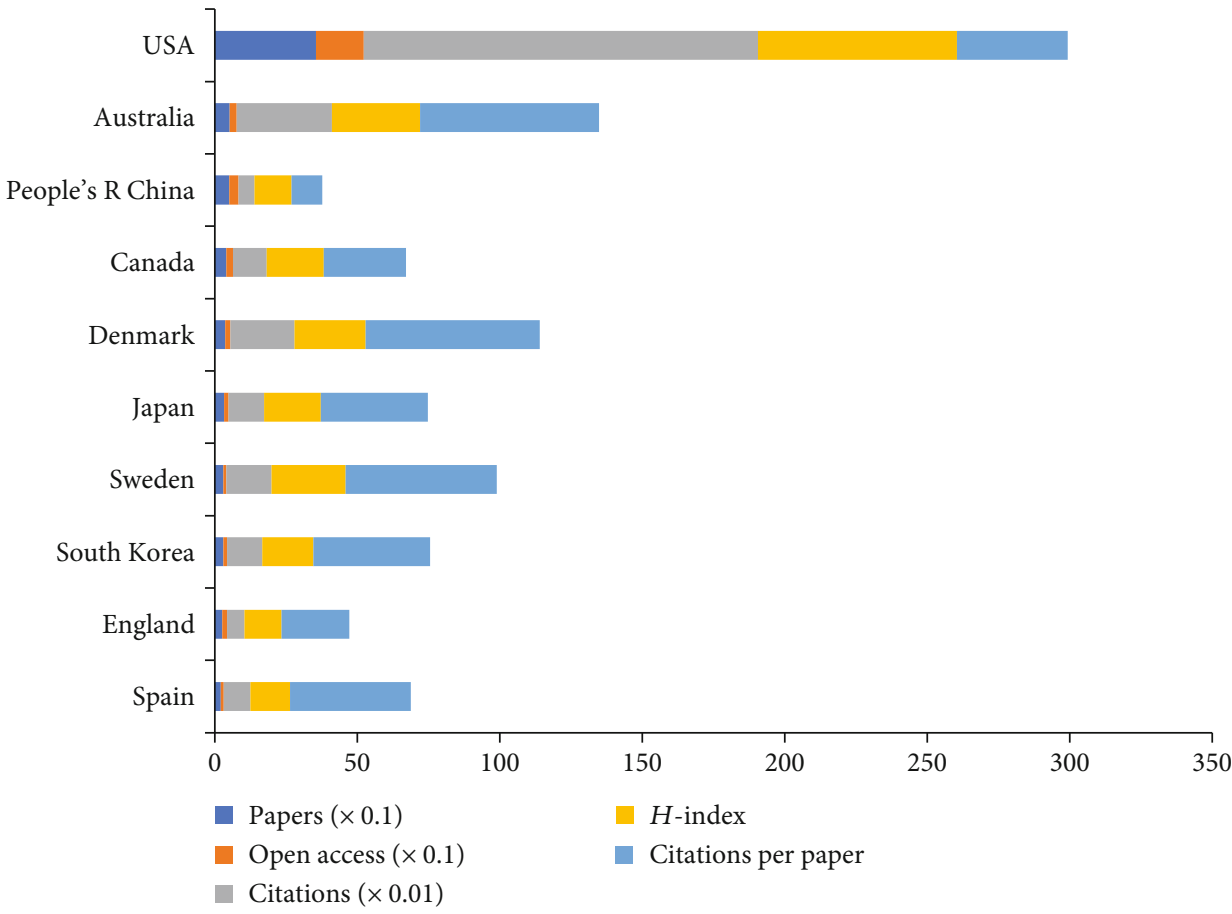

FIgURE 6: The number of papers, citations, citations per paper, and open-access papers and $H$-index of the top 10 countries.

3.7. Analysis of References. The cocitation analysis of references is shown in the timeline view in Figure 11. CiteSpace automatically generated the top 17 clusters. The modular $Q$ value shows the significance of the community structure. The modularity $Q$ score was 0.8557 (higher than 0.5 ), which indicated that the network was reasonably distributed to loosely coupled clusters. The largest cluster was labeled "neurofeedback," the second-largest clusters were "multidimensional" (\#1) and "hyperexcitability" (\#2), and the third-largest cluster (\#3) was "quisqualic acid."

3.8. Analysis of Keywords. The top keyword with the strongest citation burst since 1991 was chronic pain, followed by central pain since 1992 (Figure 12). These keywords with high citation bursts reflect the topic frontier. The current keywords with the strongest citation bursts included 


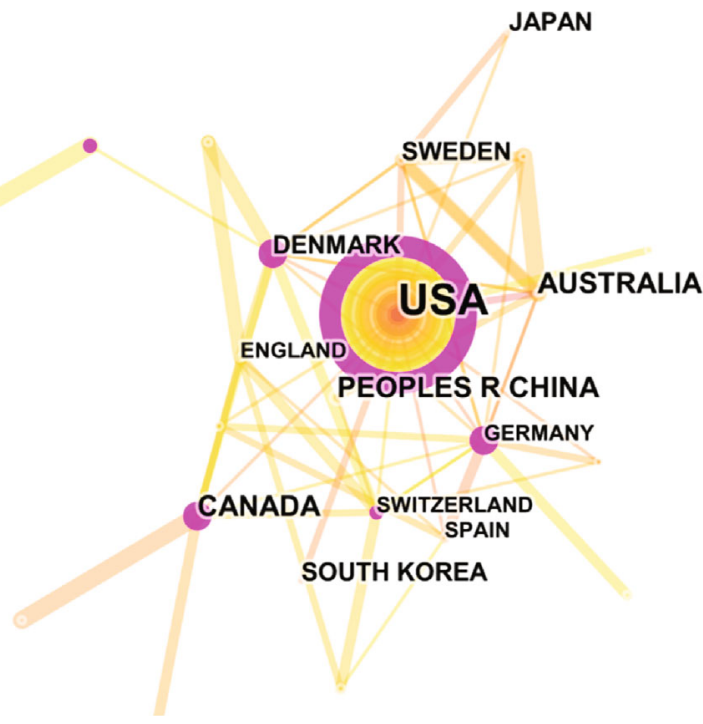

(a)

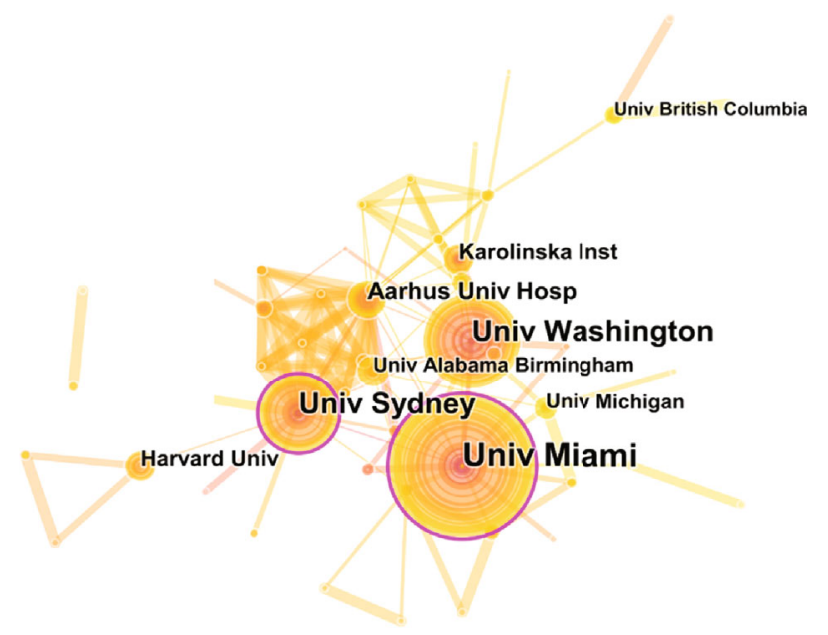

(b)

Figure 7: The analysis of countries and institutions. (a) Network map of countries/territories engaged in pain after spinal cord injury. (b) Network map of institutions engaged in pain after spinal cord injury.

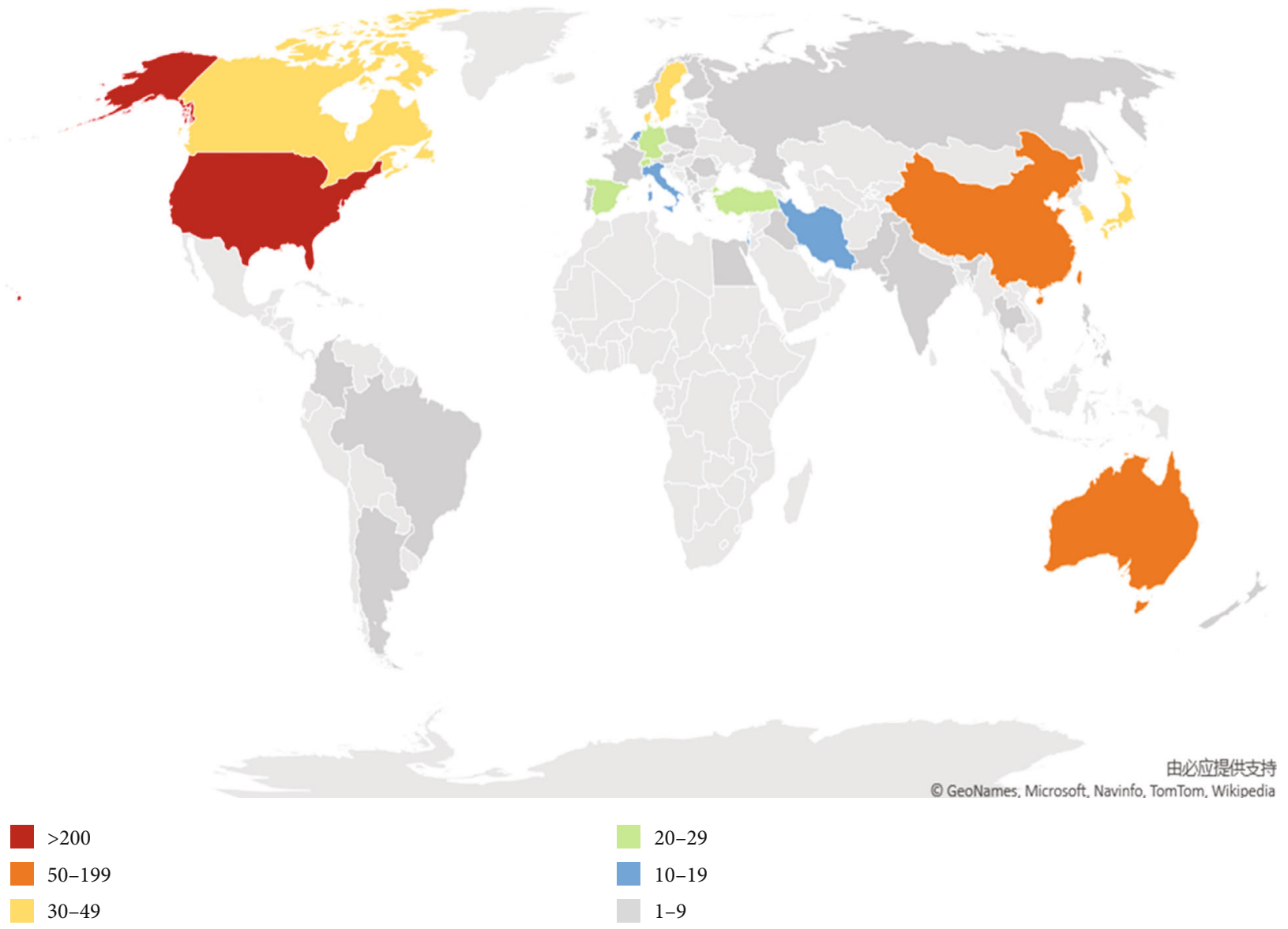

FIGURE 8: World map of the total country output based on pain after spinal cord injury.

"management" (2015-2019), "quality of life" (2016-2019), “individual” (2016-2019), “inflammation" (2016-2019), and "central sensitization" (2017-2019) amongst the top 26 keywords (chronic pain, central pain, gene-related peptide, lesion, dysesthetic pain, quisqualic pain, pain, questionnaire, double blind, severity, disability, dorsal horn neuron, neuron, 
TABLE 2: The top 10 authors, cocited authors, and cocited references in pain after spinal cord injury.

\begin{tabular}{|c|c|c|c|c|c|}
\hline Author & $\begin{array}{l}\text { Published } \\
\text { articles }\end{array}$ & Cocited author & $\begin{array}{l}\text { Cited } \\
\text { times }\end{array}$ & Cocited reference & $\begin{array}{l}\text { Cited } \\
\text { times }\end{array}$ \\
\hline Finnerup NB & 34 & Siddall PJ & 403 & $\begin{array}{l}\text { Siddall PJ, 2003, PAIN, V103, P249, } \\
\text { DOI 10.1016/S0304-3959(02)00452-9 }\end{array}$ & 67 \\
\hline Cardenas DD & 29 & Finnerup NB & 269 & $\begin{array}{c}\text { Bryce TN, 2012, SPINAL CORD, V50, P413, } \\
\text { DOI } 10.1038 / \text { sc.2011.156 }\end{array}$ & 52 \\
\hline Siddall PJ & 27 & Widerstrom-noga EG & 164 & $\begin{array}{l}\text { Hains BC, 2006, J NEUROSCI, V26, P4308, } \\
\text { DOI 10.1523/JNEUROSCI.0003-06.2006 }\end{array}$ & 44 \\
\hline Jensen MP & 26 & Jensen MP & 140 & $\begin{array}{c}\text { Widerstrom-noga E, 2008, SPINAL CORD, V46, } \\
\text { P818, DOI 10.1038/sc.2008.64 }\end{array}$ & 44 \\
\hline Richards JS & 26 & Yezierski RP & 132 & $\begin{array}{c}\text { Hulsebosch CE, 2009, BRAIN RES REV, V60, P202, } \\
\text { DOI 10.1016/j.brainresrev.2008.12.010 }\end{array}$ & 43 \\
\hline Hulsebosch CE & 22 & Rintala DH & 123 & $\begin{array}{l}\text { Turner JA, 2001, ARCH PHYS MED REHAB, V82, } \\
\text { P501, DOI 10.1053/apmr.2001.21855 }\end{array}$ & 42 \\
\hline Widerstrom-noga E & 16 & Hains BC & 117 & $\begin{array}{l}\text { Siddall PJ, 1999, PAIN, V81, P187, } \\
\text { DOI 10.1016/S0304-3959(99)00023-8 }\end{array}$ & 42 \\
\hline Widerstrom-noga EG & 16 & Cardenas DD & 107 & $\begin{array}{c}\text { Siddall PJ, 2009, SPINAL CORD, V47, P352, } \\
\text { DOI } 10.1038 / \text { sc.2008.136 }\end{array}$ & 39 \\
\hline Yezierski RP & 15 & Hulsebosch CE & 102 & $\begin{array}{c}\text { Finnerup NB, 2014, J PAIN, V15, P40, } \\
\text { DOI 10.1016/j.jpain.2013.09.008 }\end{array}$ & 38 \\
\hline Jensen TS & 13 & Melzack R & 99 & $\begin{array}{l}\text { Finnerup NB, 2012, CURR PAIN HEADACHE R, } \\
\text { V16, P207, DOI 10.1007/s11916-012-0259-x }\end{array}$ & 37 \\
\hline
\end{tabular}

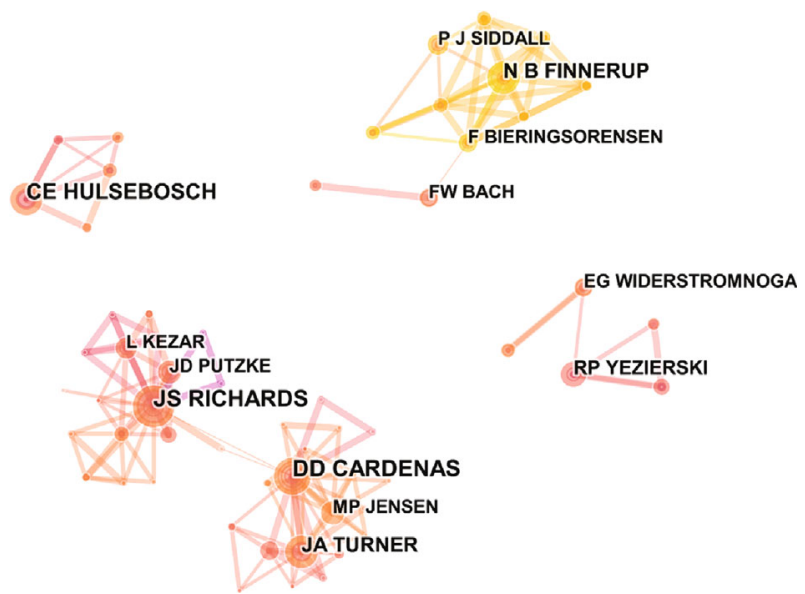

FIGURE 9: The analysis of authors. Network map of active authors that contributed to pain after spinal cord injury.

tactile allodynia, receptor, hyperexcitability, motor cortex, efficacy, quality, exercise, mechanism, management, quality of life, individual, inflammation, and central sensitization).

3.9. Characteristics of the Top 10 Papers Cited Most Frequently. Table 3 shows the top 10 papers on pain after SCI with the largest number of citations. The 10 papers had 3166 citations, which is $12.07 \%$ of all the citations of the included articles. The article of Siddall PJ [26] with the title, "A longitudinal study of the prevalence and characteristics of pain in the first 5 years following spinal cord injury," which was published in 2003 in Journal of Pain, was the most cited article (505 citations). The top 10 papers included one
[27] journal with IF $>8$, five [26, 28-31] journals with $5 \leq \mathrm{IF}<8$, three [32-34] journals with $3 \leq \mathrm{IF}<5$, and one [35] journal with $1 \leq \mathrm{IF}<3$.

\section{Discussion}

4.1. Global Trends of the Research on the Comorbidity of Pain and SCI. This paper presents a systematic overview by using bibliometric analysis to measure the studies on pain after SCI in the last three decades. The results showed that the global trend of the published works of literature on neuropathic pain after SCI had continued growth over time, indicating that pain after SCI attracted wide attention from researchers and provided a rich foundation for the follow-up research. Although the related publications showed a statistical growth year by year, the fastest growth rate of articles and openaccess publications appeared from 2015 to 2019. The fastest growth rate of the number of citations appeared from 2005 to 2009, and the related papers published in 2010-2014 had the highest $H$-index value, indicating that the quality of papers published in the 2005-2014 period was improved.

The top 20 journals contributed to 58.43\% (430) of the total number of publications on pain after SCI. Spinal Cord had a dominative contribution in terms of the number of works of literature on neuropathic pain and SCI research (11.96\%), followed by Pain (8.15\%), Archives of Physical Medicine and Rehabilitation (5.57\%), and Journal of Neurotrauma $(4.484 \%)$. The high number of citation frequency and citations per paper implied that Spinal Cord and Pain had superior quality and academic impression and were known as an unarguable mainstream subject on pain after SCI research. According to Journal Citation Reports (2019 edition), none of the top 20 journals had an IF greater than 


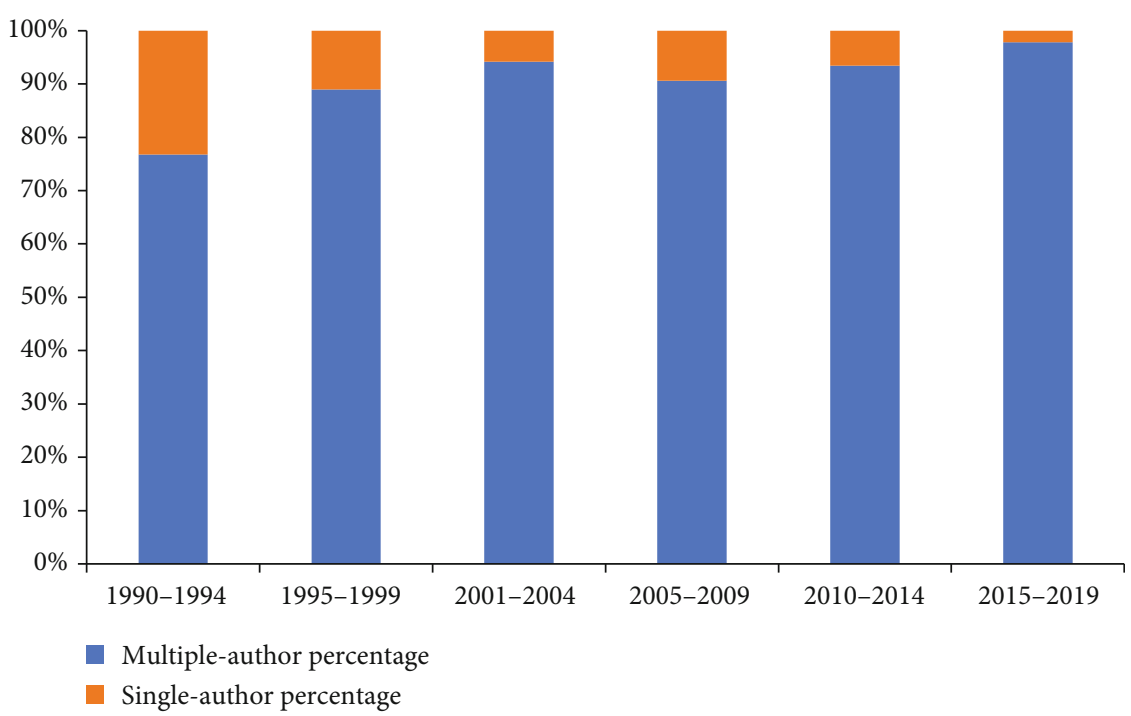

FIGURE 10: Trends in the percentage of single- vs. multiple-author articles per 5 years.

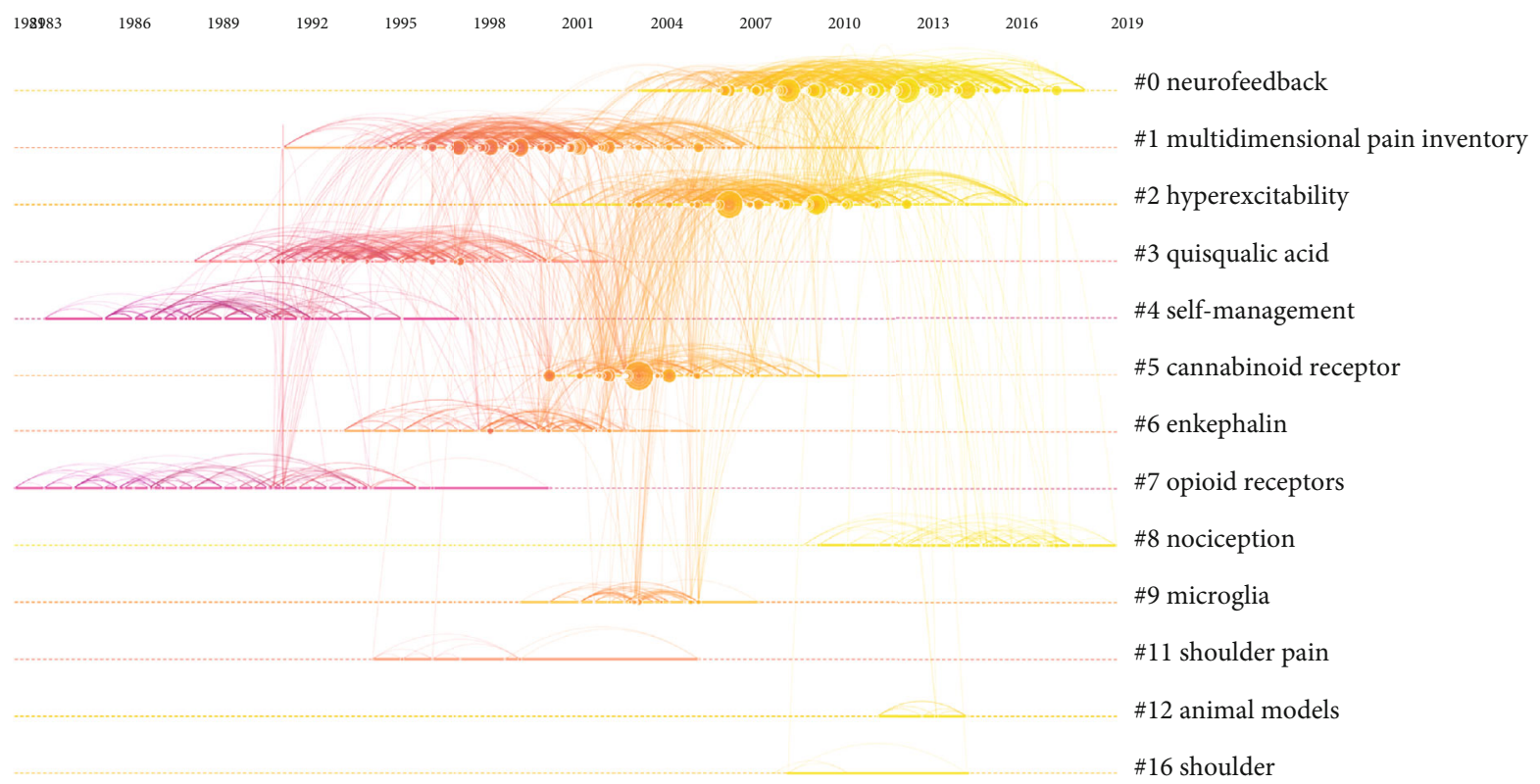

Figure 11: The analysis of references. Cocitation map (timeline view) of references from publications on pain after spinal cord injury.

10. Seven journals had an IF of 2-3 (Clinical Journal of Pain, Neuroscience Letters, Disability and Rehabilitation, Journal of Rehabilitation Medicine, Journal of Pain Research, Spine, and Molecular Pain), four journals had an IF of 3-5 (Archives of Physical Medicine and Rehabilitation, Experimental Neurology, Journal of Neurotrauma, and European Journal of Pain), and three papers had an IF of 5-10 (Neurology, Journal of Neuroscience, and Neurology). Amongst the top 20 journals, 35\% were in Q1 and 45\% were in Q2 according to the journal IF quartile in WoS. There are only three journals with IF $>5$, and the average IF of the remaining was 3.265. There was still a challenge in writing in a high IF factor journal.

Based on the quantity of related publications on pain after SCI, the USA had a dominative contribution to the number of works of literature (356), followed by Australia (53), China (52), and Canada (41). The top 10 countries included two American countries, three Asia-Pacific countries, and four European countries. Figure 7(b) shows the expansive network map of the cooperation of the countries by CiteSpace V with 97 nodes and 164 links. The link between the two nodes represents the frequency of cociting articles published by the two nodes, which implies the closeness of the connection between the two nodes. And we can easily acknowledge from Figure 7 (b) that the University of Sydney had relatively close collaborations with others. A total of 805 institutions published papers on pain after SCI. Australia had three institutions, and the USA had six institutions (University of Miami, University of Texas System, 


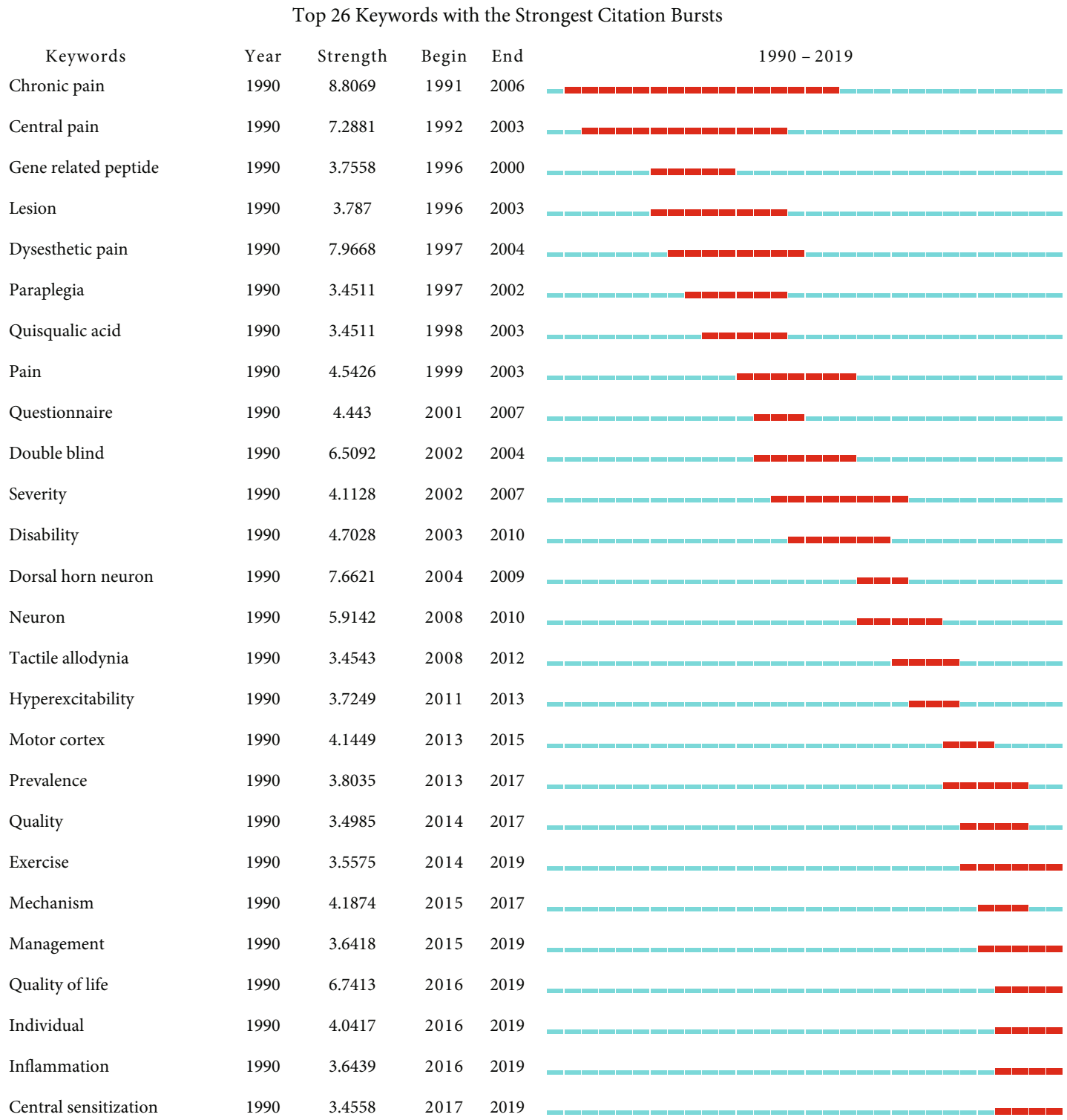

FIGURE 12: The keywords with the strongest citation bursts of publications on pain after spinal cord injury.

University of Sydney, Veterans Health Administration, US Department of Veterans Affairs, and University of Alabama System). These results indicated that the USA was the main power in this field. The top 10 institutions were mainly from the USA with the most publications. The USA, as a developed country, is at the forefront of this research.

\subsection{Research Focuses on the Comorbidity of Pain and Spine} Core Injury Research. As shown in Figure 4, clinical neurology was the most prolific research field on pain after SCI according to the subject categories of WoS (355), followed by neurosciences (279), rehabilitation (210), and anesthesiology (111). The top 10 subject categories were rehabilitation, clinical neurology, neurosciences, anesthesiology, sport sciences, critical care medicine, pharmacology, orthopedics, surgery, and experimental medicine research. According to the synthetic analysis of the number of publications and citations, the number of citations per paper, and the $H$-index, we could acknowledge that the proportions of the top three subject categories of WoS (clinical neurology, neurosciences, and rehabilitation) were all above $20 \%$ and the number of citations per paper was all above 30 , implying that the top three subject categories had superior quality and were recognized as the mainstream subject on the pain after SCI research. Based on the types of pain, the majority of the included articles involved neuropathic pain and treating pain after SCI. Amongst the top 10 types of pain (neuropathic pain, treating pain, nociceptive pain, animal models of pain, spontaneous pain, persistent pain, shoulder pain, musculoskeletal pain, low back pain, and upper extremity pain), neuropathic pain had the largest number of publications (506), citations $(16,045)$, and open-access papers (266) and the highest $H$-index value (77), indicating that neuropathic pain has attracted wide attention from researchers, and it is also an urgent problem for patients after spinal cord injury. 


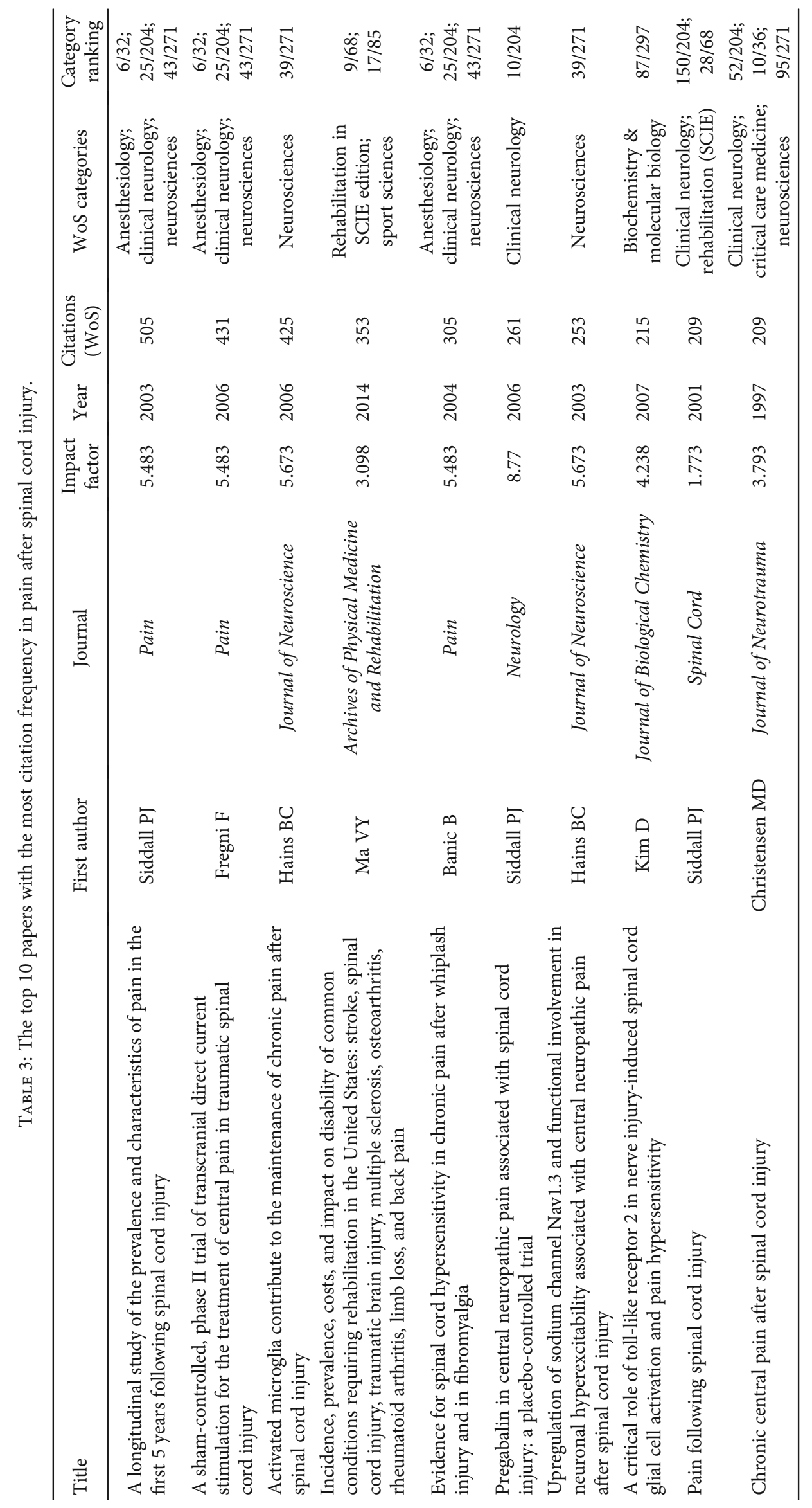


In the cocitation map of references, "neurofeedback" was labeled as the largest cluster $(\# 0)$, the second-largest clusters were "multidimensional pain inventory" (\#1) and "hyperexcitability" (\#2), and the third was "quisqualic acid" (\#3). Based on the analysis of keywords, "chronic pain" had the strongest citation bursts since 1991. The top 26 keywords by the end of 2019 included "exercise" (2014-2019), "management" (2015-2019), "quality of life" (2016-2019), "individual" (2016-2019), “inflammation" (2016-2019), and "central sensitization" (2017-2019). Because of the multiple causes of neuropathic pain, this research area is very broad. However, these publications were mainly focused on neurofeedback and pain management. Patients after spinal cord injury inevitably suffer from different degrees and types of pain, so pain management is becoming more and more important. In addition, emerging interventions to manage pain are diverse, including exercise therapy that is not limited by venue and time. At present, many clinical studies [36-39] have shown that patients with spinal cord injury have good compliance with exercise therapy to relieve pain. Sumizono et al. [36] and Ditor et al. [38] have confirmed aerobic exercise can significantly alleviate neuropathic pain in patients with spinal cord injury. And the finding of Sumizono et al. [36] indicated that aerobic exercise alleviated neuropathic pain through the regulation of glial cell activation and expression of BDNF in the ipsilateral spinal dorsal horn and the endogenous opioid system. In addition, the result of Detloff et al.'s [40] study also suggested that there is a critical therapeutic window when exercise therapy may be effective at treating SCI-induced allodynia and that there are postinjury periods when exercise can be deleterious.

4.3. Strengths and Limitations. This study was the first to combine and integrate acquired information for the bibliometric analyses of the focus issues, direction, and development trend of research studies about pain after SCI over the last 30 years. These publications were retrieved from the SCI-Expanded WoS. The publication selects a variety of journals to ensure the integrity and diversity of the data. Our study included 730 articles on pain after SCI that were published in academic journals, such as Pain, Neurology, and Journal of Neuroscience. Subject categories, the number of publications and citations, the $\mathrm{H}$-index in WoS, the collaborative analyses of journals and countries or institutions, and the cocitation analyses of references or authors and keywords were included.

This study has several limitations. This study only selected the SCI-Expanded WoS database for the retrieval of articles, and non-English papers were not included. Therefore, these factors may cause publication bias. Some influential papers may not be highly cited, whereas others are frequently cited, and the results are widely known.

\section{Conclusions}

This study provides the latest research direction for pain after SCI. This analysis can enable research teams to collaborate and promote the clinical management of pain after SCI. The initial three publications substantially increased to 47 publications from 1990 to 2019. The USA contributed the greatest number of published articles, and Neurology was the most influential journal on pain after SCI. Although this study has some limitations, it showed the common types of pain after SCI, especially neuropathic pain. According to the type of pain, 512 papers focused on neuropathic pain; thus, neuropathic pain is the most common type of pain after SCI. This historical overview of research into pain after SCI will be a useful basis for further research into development trends, focus issues, cooperators, and cooperative institutions.

\section{Data Availability}

All research data used to support the findings of this study are included within the article and the supplementary information file.

\section{Conflicts of Interest}

The authors report no conflicts of interest.

\section{Authors' Contributions}

Yi-Zu Wang and Cheng-Cheng Wu contributed equally to this work.

\section{Acknowledgments}

This work was supported by the National Natural Science Foundation of China (81871844), the Shanghai Key Lab of Human Performance (Shanghai University of Sport) (11DZ2261100), and the scientific and technological research program of the Shanghai Science and Technology Committee (Fund number: 19080503100).

\section{Supplementary Materials}

Supplementary 1. Supplementary Figure 1: overview of the paper selection process. Supplementary Figure 2: the number of papers, citations, citations per paper, open-access papers, and $H$-index of the top 10 institutions.

Supplementary 2. Supplement Supplementary Table 1: raw data on journal sources of pain after spinal cord injury. Supplementary Table 2: raw data on countries/territories involved in pain after spinal cord injury. Supplementary Table 3: raw data on institutions involved in pain after spinal cord injury.

\section{References}

[1] R. W. Teasell, S. Mehta, J. A. Aubut et al., "A systematic review of pharmacologic treatments of pain after spinal cord injury," Archives of Physical Medicine and Rehabilitation, vol. 91, no. 5, pp. 816-831, 2010.

[2] S. van Gorp, A. G. Kessels, E. A. Joosten, M. van Kleef, and J. Patijn, "Pain prevalence and its determinants after spinal cord injury: a systematic review," European Journal of Pain, vol. 19 , no. 1, pp. 5-14, 2015. 
[3] R. Wang, H. Tian, D. Guo, Q. Tian, T. Yao, and X. Kong, "Impacts of exercise intervention on various diseases in rats," Journal of Sport and Health Science, vol. 9, no. 3, pp. 211227, 2020.

[4] R. de la Garza Ramos, J. Nakhla, R. Nasser et al., "The impact of hospital teaching status on timing of intervention, inpatient morbidity, and mortality after surgery for vertebral column fractures with spinal cord injury," World Neurosurgery, vol. 99, pp. 140-144, 2017.

[5] R. Shiao and C. A. Lee-Kubli, "Neuropathic pain after spinal cord injury: challenges and research perspectives," Neurotherapeutics, vol. 15, no. 3, pp. 635-653, 2018.

[6] S. S. Chambel, I. Tavares, and C. D. Cruz, "Chronic pain after spinal cord injury: is there a role for neuron-immune dysregulation?," Frontiers in Physiology, vol. 11, p. 768, 2020.

[7] P. Henwood and J. Ellis, "Chronic Neuropathic Pain in Spinal Cord Injury: The Patient's Perspective," Pain Research \& Management, vol. 9, no. 1, pp. 39-45, 2004.

[8] N. B. Finnerup, "Pain in patients with spinal cord injury," Pain, vol. 154, Supplement 1, pp. S71-S76, 2013.

[9] S. A. Adal, M. Mackey, F. Pourkazemi, and C. E. Hiller, "The relationship between pain and associated characteristics of chronic ankle instability: a retrospective study," Journal of Sport and Health Science, vol. 9, no. 1, pp. 96-101, 2020.

[10] M. Fehlings, A. Singh, L. Tetreault, S. Kalsi-Ryan, and A. Nouri, "Global prevalence and incidence of traumatic spinal cord injury," Clinical Epidemiology, vol. 6, pp. 309331, 2014.

[11] B. Lenehan, J. Street, B. K. Kwon et al., "The epidemiology of traumatic spinal cord injury in British Columbia, Canada," Spine, vol. 37, no. 4, pp. 321-329, 2012.

[12] D. D. Cardenas, E. C. Nieshoff, K. Suda et al., "A randomized trial of pregabalin in patients with neuropathic pain due to spinal cord injury," Neurology, vol. 80, no. 6, pp. 533-539, 2013.

[13] E. J. Yoon, Y. K. Kim, H. R. Kim, S. E. Kim, Y. Lee, and H. I. Shin, "Transcranial direct current stimulation to lessen neuropathic pain after spinal cord injury: a mechanistic PET study," Neurorehabilitation and Neural Repair, vol. 28, no. 3, pp. 250259, 2014.

[14] M. D. Soler, H. Kumru, R. Pelayo et al., "Effectiveness of transcranial direct current stimulation and visual illusion on neuropathic pain in spinal cord injury," Brain, vol. 133, no. 9, pp. 2565-2577, 2010.

[15] D. Burke, O. Lennon, C. Blake et al., "An internet-delivered cognitive behavioural therapy pain management programme for spinal cord injury pain: a randomized controlled trial," European Journal of Pain, vol. 23, no. 7, pp. 1264-1282, 2019.

[16] M. Saab, J. Dartus, R. Erivan, N. Reina, M. Ollivier, and P. Devos, "Publication output of French orthopedic and trauma surgeons: quantitative and qualitative bibliometric analysis of their scientific production in orthopedics and other medical fields," Orthopaedics \& Traumatology: Surgery \& Research, vol. 105, no. 8, pp. 1439-1446, 2019.

[17] X. Zhu, X. Niu, T. Li, C. Liu, L. Chen, and G. Tan, "Identification of research trends concerning application of stent implantation in the treatment of pancreatic diseases by quantitative and biclustering analysis: a bibliometric analysis," PeerJ, vol. 7, article e7674, 2019.

[18] P. Sebo, J. P. Fournier, and H. Maisonneuve, "Is statistician involvement as co-author associated with reduced time to publication of quantitative research in general medical jour- nals? A bibliometric study," Family Practice, vol. 36, no. 4, pp. 431-436, 2019.

[19] S. Guo, L. Wang, Y. Xie et al., "Bibliometric and visualized analysis of stem cells therapy for spinal cord injury based on Web of Science and CiteSpace in the last 20 years," World Neurosurgery, vol. 132, pp. e246-e258, 2019.

[20] K. Zheng and X. Wang, "Publications on the association between cognitive function and pain from 2000 to 2018: a bibliometric analysis using CiteSpace," Medical Science Monitor, vol. 25, pp. 8940-8951, 2019.

[21] S.-Q. Wang, Y. Q. Gao, C. Zhang, Y. J. Xie, J. X. Wang, and F. Y. Xu, "A bibliometric analysis using CiteSpace of publications from 1999 to 2018 on patient rehabilitation after total knee arthroplasty," Medical Science Monitor, vol. 26, article e920795, 2020.

[22] R. Wang, L. M. Weng, M. S. Peng, and X. Q. Wang, "Exercise for low back pain: a bibliometric analysis of global research from 1980 to 2018," Journal of Rehabilitation Medicine, vol. 52, no. 4, article jrm00052, 2020.

[23] Y. M. Chen and X. Q. Wang, "Bibliometric analysis of exercise and neuropathic pain research," Journal of Pain Research, vol. 13, pp. 1533-1545, 2020.

[24] L. M. Weng, Y. L. Zheng, M. S. Peng, T. T. Chang, B. Wu, and X. Q. Wang, "A bibliometric analysis of nonspecific low back pain research," Pain Research \& Management, vol. 2020, article 5396734, 13 pages, 2020.

[25] X. Q. Wang, M. S. Peng, L. M. Weng, Y. L. Zheng, Z. J. Zhang, and P. J. Chen, "Bibliometric study of the comorbidity of pain and depression research," Neural Plasticity, vol. 2019, Article ID 1657498, 16 pages, 2019.

[26] P. J. Siddall, J. M. McClelland, S. B. Rutkowski, and M. J. Cousins, "A longitudinal study of the prevalence and characteristics of pain in the first 5 years following spinal cord injury," Pain, vol. 103, no. 3, pp. 249-257, 2003.

[27] S. P. Kruszewski, J. A. Shane, P. . J. Siddall et al., "Pregabalin in central neuropathic pain associated with spinal cord injury: a placebo-controlled trial," Neurology, vol. 68, no. 24, pp. 2158-2160, 2007.

[28] F. Fregni, P. S. Boggio, M. C. Lima et al., "A sham-controlled, phase II trial of transcranial direct current stimulation for the treatment of central pain in traumatic spinal cord injury," Pain, vol. 122, no. 1, pp. 197-209, 2006.

[29] B. Hains and S. Waxman, "Activated microglia contribute to the maintenance of chronic pain after spinal cord injury," The Journal of neuroscience : the official journal of the Society for Neuroscience, vol. 26, no. 16, pp. 4308-4317, 2006.

[30] B. Banic, S. Petersen-Felix, O. K. Andersen et al., "Evidence for spinal cord hypersensitivity in chronic pain after whiplash injury and in fibromyalgia," Pain, vol. 107, no. 1, pp. 7-15, 2004.

[31] B. C. Hains, J. P. Klein, C. Y. Saab, M. J. Craner, J. A. Black, and S. G. Waxman, "Upregulation of sodium channel Nav1.3 and functional involvement in neuronal hyperexcitability associated with central neuropathic pain after spinal cord injury," The Journal of Neuroscience, vol. 23, no. 26, pp. 8881-8892, 2003.

[32] V. Y. Ma, L. Chan, and K. J. Carruthers, "Incidence, prevalence, costs, and impact on disability of common conditions requiring rehabilitation in the United States: stroke, spinal cord injury, traumatic brain injury, multiple sclerosis, osteoarthritis, rheumatoid arthritis, limb loss, and back pain," 
Archives of Physical Medicine and Rehabilitation, vol. 95, no. 5, pp. 986-995.e1, 2014.

[33] D. Kim, M. A. Kim, I. H. Cho et al., "A critical role of toll-like receptor 2 in nerve injury-induced spinal cord glial cell activation and pain hypersensitivity," The Journal of Biological Chemistry, vol. 282, no. 20, pp. 14975-14983, 2007.

[34] M. D. Christensen and C. E. Hulsebosch, "Chronic central pain after spinal cord injury," Journal of Neurotrauma, vol. 14, no. 8, pp. 517-537, 1997.

[35] P. J. Siddall and J. D. Loeser, "Pain following spinal cord injury," Spinal Cord, vol. 39, no. 2, pp. 63-73, 2001.

[36] M. Sumizono, H. Sakakima, S. Otsuka et al., "The effect of exercise frequency on neuropathic pain and pain-related cellular reactions in the spinal cord and midbrain in a rat sciatic nerve injury model," Journal of Pain Research, vol. 11, pp. 281-291, 2018.

[37] C. Norrbrink, T. Lindberg, K. Wahman, and A. Bjerkefors, "Effects of an exercise programme on musculoskeletal and neuropathic pain after spinal cord injury-results from a seated double-poling ergometer study," Spinal Cord, vol. 50, no. 6, pp. 457-461, 2012.

[38] D. S. Ditor, A. E. Latimer, K. A. Martin Ginis, K. P. Arbour, N. McCartney, and A. L. Hicks, "Maintenance of exercise participation in individuals with spinal cord injury: effects on quality of life, stress and pain," Spinal Cord, vol. 41, no. 8, pp. 446-450, 2003.

[39] K. A. Cratsenberg, C. E. Deitrick, T. K. Harrington et al., "Effectiveness of exercise programs for management of shoulder pain in manual wheelchair users with spinal cord injury," Journal of Neurologic Physical Therapy, vol. 39, no. 4, pp. 197-203, 2015.

[40] M. R. Detloff, D. Quiros-Molina, A. S. Javia et al., "Delayed exercise is ineffective at reversing aberrant nociceptive afferent plasticity or neuropathic pain after spinal cord injury in rats," Neurorehabilitation and Neural Repair, vol. 30, no. 7, pp. 685700, 2016. 